\title{
Ethnic differences in self-harm, rates, characteristics and service provision: three-city cohort study
}

Jayne Cooper, Elizabeth Murphy, Roger Webb, Keith Hawton, Helen Bergen, Keith Waters and Navneet Kapur

\section{Background}

Studies of self-harm in Black and minority ethnic (BME) groups have been restricted to single geographical areas, with few studies of Black people.

\section{Aims}

To calculate age- and gender-specific rates of self-harm by ethnic group in three cities and compare characteristics and outcomes.

\section{Method}

A population-based self-harm cohort presenting to five emergency departments in three English cities during 2001 to 2006.

\section{Results}

A total of 20574 individuals (16-64 years) presented with self-harm; ethnicity data were available for $75 \%$. Rates of self-harm were highest in young Black females (16-34 years) in all three cities. Risk of self-harm in young South Asian people varied between cities. Black and minority ethnic groups were less likely to receive a psychiatric assessment and to re-present with self-harm.

\section{Conclusions}

Despite the increased risk of self-harm in young Black females fewer receive psychiatric care. Our findings have implications for assessment and appropriate management for some BME groups following self-harm.

\section{Declaration of interest}

N.K. is Chair of the NICE Guidelines Development Group for the new self-harm guidelines.
Variation in rates of suicide in Black and minority ethnic (BME) groups have been reported in different countries. ${ }^{1,2}$ Rates of suicide $^{3,4}$ and self-harm ${ }^{5-7}$ may be lower in BME groups than White groups overall, but this finding may obscure differences in age- and gender-specific groups. Also, rates of suicide and self-harm within ethnic minority groups may fluctuate according to area, with a decline in relative risk of suicide and self-harm where there is a larger density of minority populations. ${ }^{8,9}$ Previous research on BME groups in the UK has generally been conducted in single geographical areas, ${ }^{10}$ and self-harm studies have been limited by small sample size, with few studies of people of African-Caribbean origin. ${ }^{11}$ A report on suicide prevention for BME groups in England calls for better information on rates and risk factors for suicide or behaviours that increase the likelihood of suicide. ${ }^{12}$ We have conducted a study of self-harm in different minority ethnic groups using a multicentre database of self-harm in three geographical areas in England. Our objectives were to compare ethnic groups (that is, White, South Asian and Black African-Caribbean) with regard to: age- and gender-specific rates of self-harm in different cities; sociodemographic and clinical characteristics; clinical management following self-harm; and risk of repetition of self-harm.

\section{Method}

\section{Study design and data collection}

We conducted a prospective, multicentre cohort study, identifying all episodes of self-harm presenting to emergency departments in general hospitals in Manchester (three hospitals), Derby (two hospitals) and Oxford (one hospital). The study hospitals were chosen on a pragmatic basis - the centres included were those that had established monitoring systems. The cities of Manchester,
Derby and Oxford have different profiles (Table 1), with ethnic groups forming a greater proportion of the general population in Manchester. According to the UK government's Index of Multiple Deprivation, where 353 local authority areas in England were scored on a number of indicators (covering a range of economic, social and health issues) into a single deprivation score, ${ }^{13}$ Manchester was ranked fourth (worst), Derby sixty-ninth and Oxford one hundred and fifty-fifth.

Data were collected using established monitoring systems in the three centres, described in full elsewhere. ${ }^{14,15}$ Self-harm attendances were identified via detailed examination of computerised emergency department records and defined consistently across all three centres as intentional self-poisoning or self-injury, irrespective of motivation and degree of suicidal intent. ${ }^{16}$ Most participants received a psychosocial assessment from emergency department staff and/or mental health specialists. For assessed participants, clinicians recorded a wide range of sociodemographic and clinical information using research assessment forms. For participants who were not assessed (for example, because they refused or took early discharge), basic information was collected by research clerks from medical records. In Manchester, data were collected for non-assessed individuals from computerised patient record systems from September 2002 onwards. Information on ethnicity was obtained where available and recorded either by the assessing clinician or from the hospital patient records system, using standard UK national 2001 census categories. We combined ethnic groups on a pragmatic basis. Our categories were in line with previous research, ${ }^{17}$ namely: 'South Asian', including all people of Pakistani, Indian, or Bangladeshi origin; 'Black', including Black African-Caribbean or Black Other; 'White', including White British, Irish or White Other. We chose not to include those of 'other ethnicity' because of relatively low numbers and diverse composition of this 


\begin{tabular}{|c|c|c|c|c|}
\hline Characteristic & England & Manchester & Derby & Oxford \\
\hline \multicolumn{5}{|l|}{$\%$ of population } \\
\hline Unemployed, 16-74 years & 2 & 4 & 3 & 2 \\
\hline Lone parents, $16-29$ years & 5 & 8 & 6 & 3 \\
\hline No qualifications known, $16-74$ years & 26 & 28 & 28 & 18 \\
\hline 'Non-White' - all ages & 9 & 19 & 12 & 13 \\
\hline Black - all ages & 2 & 5 & 2 & 3 \\
\hline South Asian - all ages & 4 & 8 & 8 & 4 \\
\hline \multicolumn{5}{|l|}{$\%$ of all South Asian people } \\
\hline Indian & 51 & 18 & 49 & 40 \\
\hline Pakistani & 35 & 71 & 50 & 45 \\
\hline Bangladeshi & 14 & 11 & 1 & 15 \\
\hline
\end{tabular}

miscellaneous category. An upper age limit of 64 years was also applied because of low numbers of older people who self-harmed from ethnic minority groups.

Data were analysed for a 6-year study period for Derby and Oxford (1 January 2001 to 31 December 2006). For Manchester, complete data for both assessed and non-assessed individuals were available from the 1 September 2002 and so data were analysed for just over 4 years (ending 31 December 2006).

\section{Statistical analyses}

The analyses were carried out using Stata version 10 for Windows. They were based on each individual's first presentation for self-harm during the study period. Two sets of analyses were performed.

First, self-harm rates per 1000 person-years were calculated for individuals aged between 16 and 64 years (this age range ensured consistency with the age bands in the 2001 Census data) ${ }^{18}$ and with a postcode within the city catchment area of each of the hospitals in Manchester, Derby and Oxford. Approximate person-years at risk were generated by multiplying the ethnic group, gender and age-specific population estimates for each catchment area by the applicable study period for that centre. Incidence rate ratios (and their 95\% confidence intervals) for ethnic groups compared with White groups, city, age and gender were calculated from Poisson regression models, with no significant evidence of overdispersion.

Second, differences between South Asian and Black people compared with White people were explored with respect to characteristics and clinical outcomes following the first episode of self-harm in the study period (index episode) for all individuals aged between 16 and 64 years who attended any of the study hospitals with self-harm, regardless of area of their residence. Statistical significance was assessed using chi-squared tests for method of self-harm, sociodemographic characteristics, precipitating factors and clinical characteristics. Analyses were performed separately for males and females. Analysis of clinical management outcomes (as percentages) following self-harm was conducted using log-binomial regression to estimate risk ratios, with variance estimates corrected for hospital clustering effects. Finally, 12-month rates of repetition of self-harm were calculated based on the proportion of individuals re-presenting within 12 months of index episode (excluding individuals without a full 12-month follow-up period). Log-binomial regression was used to examine differences in the risk of repetition.

\section{Ethical approval}

Oxford and Derby both have approval from local health/ psychiatric research ethics committees to collect data on self-harm for local monitoring and multicentre projects. Self-harm monitoring in Manchester is part of a clinical audit system, and has been ratified by the local research ethics committee. All monitoring systems are fully compliant with the provisions of the Data Protection Act of 1998. All centres also have approval under Section 251 of the NHS Act 2006 (formerly section 60 of the Health and Social Care Act 2001) regarding the use of patient-identifiable information.

\section{Results}

During the study period there was a total of 33314 episodes of self-harm by 20574 individuals aged 16 to 64 years. Ethnicity data were available for 15350 individuals (level of completeness overall 75\%: Manchester 79\%, Oxford 73\% and Derby 69\%). Data were analysed for 14997 individuals, excluding the 353 individuals of 'other ethnicity' from the analysis.

\section{Rates of self-harm}

Analysis of rates of self-harm was conducted for individuals of White, Black or South Asian ethnicity $(n=8401)$ resident within defined city population areas of each of the centres' catchment areas (Table 2). Rates of self-harm in young Black females were highest in all three cities. The pooled rate ratio for Black females aged 16-34 years compared with White females of the same age group was 1.70 (95\% CI 1.46-1.98). When we conducted a conservative sensitivity analysis, ascribing all missing ethnicity data as relating to White persons, the rate ratio (RR) was attenuated but remained significantly elevated $(R R=1.21,95 \%$ CI 1.04-1.40). Combining data across the cities, there was no difference in risk of self-harm in South Asian females aged 1634 years compared with White females of the same age ( RR $=0.99,95 \%$ CI $0.87-1.11)$.

We tested for differences in age/gender-specific rates between cities using a Wald chi-squared test for heterogeneity. Compared with White people, the rate ratios in South Asian and in Black people varied significantly by centre in young people aged 16-34 years (in males: $\chi^{2}=17.9, \quad P=0.001 ;$ females: $\chi^{2}=11.10$, $P=0.03$ ), that is, ethnicity did not have the same risk or protective effects in all cities. However, there was no evidence of heterogeneity in older people aged 35-64 years of either gender (males: $\chi^{2}=3.6$, $P=0.46$; females: $\chi^{2}=2.9, P=0.57$ ).

In comparison with White groups, there were significantly higher rate ratios for young Black females in all three cities (Table 3 ). In contrast, rate ratios in young Black males did not differ materially from those of young White males. There were lower rate ratios in older Black people of both genders compared with White people (Table 3), a difference that reached significance in Manchester. There was variation in relative risk in South Asian 
Table 2 Numbers, person-years denominators and self-harm rates per $1000 \times$ city, gender, age and ethnic groupa

\begin{tabular}{|c|c|c|c|c|c|c|c|c|c|}
\hline & \multicolumn{3}{|c|}{ White } & \multicolumn{3}{|c|}{ South Asian } & \multicolumn{3}{|c|}{ Black } \\
\hline & $\begin{array}{l}\text { Self-harm } \\
(n=7564)\end{array}$ & $\begin{array}{l}\text { Person } \\
\text { years }\end{array}$ & $\begin{array}{l}\text { Rate/ } \\
1000\end{array}$ & $\begin{array}{l}\text { Self-harm } \\
(n=499)\end{array}$ & $\begin{array}{l}\text { Person- } \\
\text { years }\end{array}$ & $\begin{array}{l}\text { Rate/ } \\
1000\end{array}$ & $\begin{array}{l}\text { Self-harm } \\
(n=338)\end{array}$ & $\begin{array}{l}\text { Person- } \\
\text { years }\end{array}$ & $\begin{array}{l}\text { Rate/ } \\
1000\end{array}$ \\
\hline \multicolumn{10}{|l|}{ Manchester } \\
\hline \multicolumn{10}{|l|}{ Males } \\
\hline $16-34$ years & 955 & 224263 & 4.3 & 64 & 28409 & 2.3 & 52 & 11938 & 4.4 \\
\hline $35-64$ years & 778 & 227972 & 3.4 & 19 & 16553 & 1.1 & 21 & 12216 & 1.7 \\
\hline \multicolumn{10}{|l|}{ Females } \\
\hline $16-34$ years & 1526 & 231361 & 6.6 & 193 & 28929 & 6.7 & 134 & 13030 & 10.3 \\
\hline $35-64$ years & 939 & 229445 & 4.1 & 31 & 16493 & 1.9 & 35 & 13312 & 2.6 \\
\hline \multicolumn{10}{|l|}{ Derby } \\
\hline \multicolumn{10}{|l|}{ Males } \\
\hline $16-34$ years & 504 & 148362 & 3.4 & 35 & 18828 & 1.9 & 12 & 3102 & 3.9 \\
\hline $35-64$ years & 374 & 215448 & 1.7 & 9 & 14514 & 0.6 & 9 & 5148 & 1.7 \\
\hline \multicolumn{10}{|l|}{ Females } \\
\hline $16-34$ years & 674 & 151464 & 4.4 & 58 & 19356 & 3.0 & 21 & 3054 & 6.9 \\
\hline 35-64 years & 450 & 216690 & 2.1 & 13 & 14574 & 0.9 & 8 & 5184 & 1.5 \\
\hline \multicolumn{10}{|l|}{ Oxford } \\
\hline \multicolumn{10}{|l|}{ Males } \\
\hline $16-34$ years & 317 & 139074 & 2.3 & 24 & 7584 & 3.2 & 13 & 3534 & 3.7 \\
\hline $35-64$ years & 236 & 111294 & 2.1 & 3 & 4284 & 0.7 & 3 & 3690 & 0.8 \\
\hline \multicolumn{10}{|l|}{ Females } \\
\hline $16-34$ years & 544 & 136530 & 4.0 & 41 & 7776 & 5.3 & 25 & 3948 & 6.3 \\
\hline $35-64$ years & 267 & 110496 & 2.4 & 9 & 4536 & 2.0 & 5 & 3624 & 1.4 \\
\hline
\end{tabular}

groups relative to White people, with significantly lower rate ratios in young people of both genders in Derby, a lower relative risk in males in Manchester, but no difference in either gender in Oxford. For older South Asian people relative rates were lower than in White people in both genders in all three cities, the differences being significant in Manchester and Derby.

\section{Characteristics}

Analyses of sociodemographics, precipitating factors and clinical characteristics were conducted for individuals of White, Black or South Asian ethnicity $\times$ gender regardless of area of residence (online Tables DS1 and DS2). In both genders, ethnic minority groups (Black and South Asian) were younger than the White groups, and less likely to have clinical characteristics known to increase risk of further suicidal behaviour compared with their White peers (that is, alcohol use within $6 \mathrm{~h}$ of the self-harm episode, previous self-harm, history of psychiatric treatment).

Females

There were some differences between ethnic groups in females. White females were more likely to present with self-injury (mostly cutting) as a method of harm, compared with South Asian and Black females, who were more likely to self-poison using non-ingestible substances (mostly cleaning fluids). South Asian females were more likely to be married and live with their partner/husband or relatives and Black females were more likely to be single than White females. Differences in employment status were observed with South Asian females more likely to be classified under household duties; Black females were more likely to be unemployed; and females in both ethnic minority groups were more likely to be students compared with White females. Although problems in relationships with partner was the most common precipitant in all groups, South Asian females were significantly more likely to cite relationship problems with their partner/husband and family than White females. South Asian females and Black females were significantly less likely to report a number of other precipitating problems than White females, apart from housing problems, which were more common in Black females.

\section{Males}

Significant differences in method of harm were observed between Black and White males. They were more likely to self-injure other than by cutting (using more violent methods of harm such as hanging and self-asphyxiation) and self-poison using

\begin{tabular}{|c|c|c|}
\hline & South Asian & Black \\
\hline & $\mathrm{RR}^{\mathrm{a}}(95 \% \mathrm{Cl})$ & $\mathrm{RR}^{\mathrm{a}}(95 \% \mathrm{Cl})$ \\
\hline \multicolumn{3}{|l|}{ Manchester } \\
\hline \multicolumn{3}{|l|}{ Males } \\
\hline 16-34 years & $0.53(0.41-0.68)$ & 1.02 (0.77-1.35) \\
\hline $35-64$ years & $0.34(0.21-0.53)$ & $0.50(0.33-0.78)$ \\
\hline \multicolumn{3}{|l|}{ Females } \\
\hline 16-34 years & $1.01(0.87-1.17)$ & $1.56(1.31-1.86)$ \\
\hline $35-64$ years & $0.46(0.32-0.66)$ & $0.64(0.46-0.90)$ \\
\hline \multicolumn{3}{|l|}{ Derby } \\
\hline \multicolumn{3}{|l|}{ Males } \\
\hline 16-34 years & $0.55(0.39-0.77)$ & $1.14(0.64-2.02)$ \\
\hline 35-64 years & $0.36(0.18-0.69)$ & $1.01(0.52-1.95)$ \\
\hline \multicolumn{3}{|l|}{ Females } \\
\hline 16-34 years & $0.67(0.51-0.88)$ & 1.55 (1.00-2.39) \\
\hline 35-64 years & $0.43(0.25-0.75)$ & $0.74(0.37-1.50)$ \\
\hline \multicolumn{3}{|l|}{ Oxford } \\
\hline \multicolumn{3}{|l|}{ Males } \\
\hline 16-34 years & $1.39(0.92-2.10)$ & $1.61(0.93-2.81)$ \\
\hline 35-64 years & $0.33(0.11-1.03)$ & $0.38(0.12-1.20)$ \\
\hline \multicolumn{3}{|l|}{ Females } \\
\hline 16-34 years & $1.32(0.96-1.82)$ & $1.59(1.06-2.37)$ \\
\hline $35-64$ years & $0.82(0.42-1.60)$ & $0.57(0.24-1.38)$ \\
\hline
\end{tabular}




\begin{tabular}{|c|c|c|c|c|c|c|c|c|c|c|}
\hline \multirow[b]{2}{*}{ Clinical management outcome } & \multicolumn{2}{|c|}{ White $(n=7938)$} & \multicolumn{4}{|c|}{ South Asian $(n=459)$} & \multicolumn{4}{|c|}{ Black $(n=288)$} \\
\hline & $n$ & $\%$ & $n$ & $\%$ & $\mathrm{RR}$ & $95 \% \mathrm{Cl}$ & $n$ & $\%$ & $\mathrm{RR}$ & $95 \% \mathrm{Cl}$ \\
\hline \multicolumn{11}{|l|}{ Assessment ${ }^{\mathrm{b}}$} \\
\hline Specialist psychiatric assessment & 5756 & 73 & 289 & 63 & 0.9 & $0.7-1.03$ & 186 & 65 & 0.9 & $0.8-0.98$ \\
\hline \multicolumn{11}{|l|}{ Clinical management ${ }^{b, c}$} \\
\hline Psychiatric referral & 2651 & 33 & 81 & 18 & 0.5 & $0.5-0.6$ & 60 & 21 & 0.6 & $0.5-0.8$ \\
\hline Alcohol or drug services referral/told to see & 344 & 4 & 2 & 0.4 & 0.1 & $0.1-0.2$ & 10 & 3 & 0.8 & $0.3-2.1$ \\
\hline Other services referral/told to see & 1893 & 24 & 97 & 21 & 0.9 & $0.6-1.3$ & 59 & 20 & 0.9 & $0.6-1.2$ \\
\hline General practitioner referral & 4710 & 59 & 262 & 57 & 1.0 & $0.8-1.1$ & 154 & 53 & 0.9 & $0.9-0.98$ \\
\hline No formal follow-up & 1555 & 20 & 142 & 31 & 1.6 & $0.98-2.5$ & 97 & 34 & 1.7 & $1.00-2.9$ \\
\hline Self-harm repetition $^{\mathrm{d}}$ & 1646 & 24 & 49 & 13 & 0.5 & $0.4-0.7$ & 31 & 13 & 0.6 & $0.4-0.8$ \\
\hline \multicolumn{11}{|c|}{$\begin{array}{l}\text { a. Rate ratios (RR) that reach statistical significance }(P<0.05) \text { are highlighted in bold. Rounding to nearest first decimal point. } \\
\text { b. Adjusted for clustering by hospital. (There were no missing data for these variables.) } \\
\text { C. An individual may have more than one referral. } \\
\text { d. Self-harm repetition following re-presentation to the emergency department (i.e. repetition within } 12 \text { months of index episode based on all individuals with at least } 12 \text { months } \\
\text { of follow-up data within the study period). }\end{array}$} \\
\hline
\end{tabular}

non-ingestible substances. South Asian males were more likely to live with a partner or relative and cite relationship problems with their family than White males. Ethnic minority males were more likely to be students than White males.

\section{Clinical management and outcome}

Analyses of clinical management following self-harm showed that young Black females were less likely to receive a specialist psychiatric assessment compared with White females (Table 4). Ethnic minority groups of both genders were less likely to present to the emergency departments within the study hospitals with further self-harm (Tables 4 and 5). We fitted extra models adjusting for age in both genders but estimates were materially unaltered.

\section{Females}

Females in both ethnic minority groups were considerably less likely to be referred for psychiatric out-patient or in-patient care following self-harm compared with White females. Black females were also less likely to be referred to their general practitioner (GP) or receive formal follow-up arrangements.

\section{Males}

Compared with White men, following self-harm, Black males were less likely to be referred to their GP and South Asian males were less likely to be referred to any other service.

\section{Discussion}

\section{Main findings}

Our main result was that across all three cities young Black females were at increased risk of self-harm. We also found differences in clinical management, with BME groups being less likely to receive a specialist psychiatric assessment and psychiatric follow-up services than the White population. In addition both minority ethnic groups in the older age range had a lower risk in all cities, and there was a variation in rates between cities among young South Asian males and females.

To our knowledge this is the first study to show significantly higher rates of self-harm in young Black females across a number of cities using large population based databases. A previous study in the UK over 20 years ago did suggest that there may be an elevated risk of self-harm in this group, ${ }^{19}$ although these findings were limited by small sample size and data confined to one hospital. A more contemporary study among people with recent previous contact with psychiatric services showed a higher standardised mortality ratio for suicide in Black African and Caribbean females aged 25-39 compared with their White peers. ${ }^{4}$ Our finding of lower rates of self-harm in older males and females in both ethnic minority groups are consistent with previous studies. ${ }^{6,11}$ We did not find the high rates of self-harm previously reported in young South Asian females ${ }^{11}$ across the centres in our study.

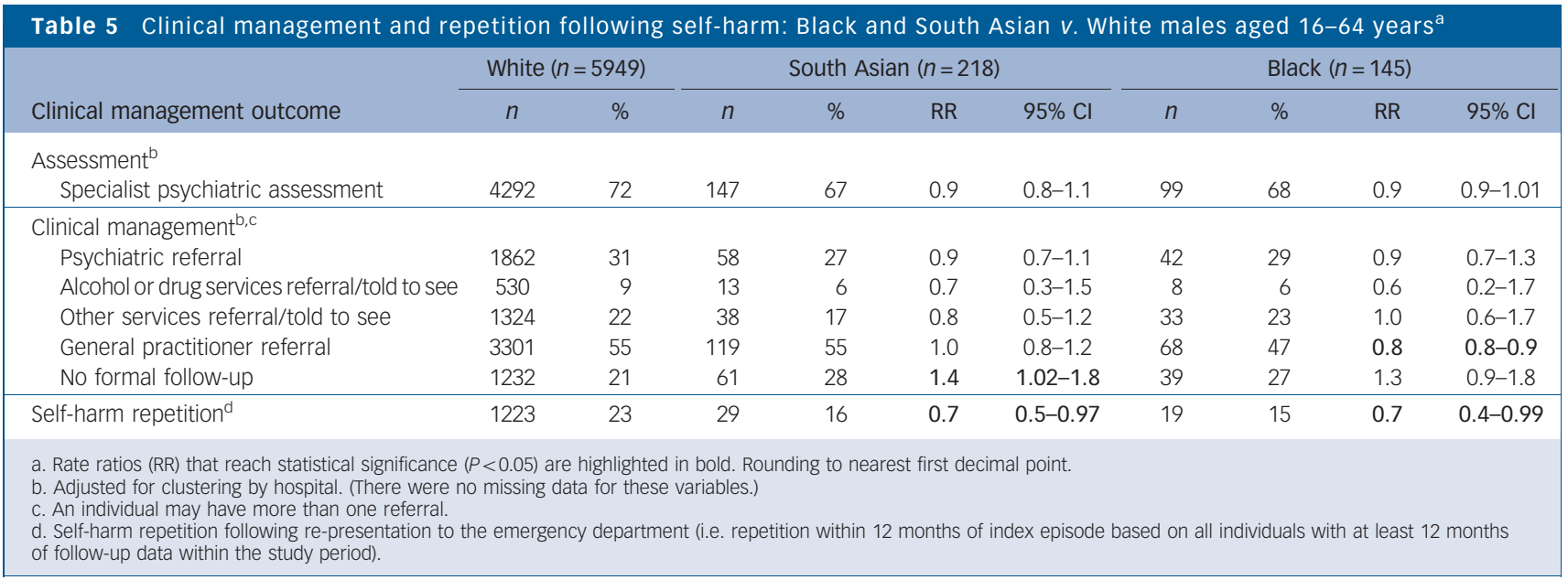




\section{Interpretation of findings}

Several of our findings require further explanation. High rates in some BME groups may be explained by characteristics that confer greater vulnerability. Poor outcome may be influenced by complex socioeconomic factors ${ }^{20}$ or may be culturally specific with differences between age and gender groups. We lacked the necessary explanatory variables to test these hypotheses. However, young Black females who self-harm may be experiencing greater social adversity, as in our cohort they were more likely to be unemployed and report housing problems compared with White women. We found that people from ethnic minority groups were more likely to be students than their White counterparts. Academic pressure may also have contributed to increased rates of self-harm, especially in women. ${ }^{21,22}$ Previous studies examining high rates of psychosis in BME groups, particularly in young Black-Caribbeans, suggest that socioeconomic factors contribute part of the explanation. ${ }^{23,24}$

The lower rates of self-harm in young Black males across centres deserves further investigation. Previous studies have found increased risk of mental illness and higher rates of completed suicide in this group compared with the White reference group. ${ }^{4,25}$ Contemporary mainstream hip-hop epitomises 'Black' youth culture and places emphasis on strength, aggression and virility. However, stereotypical 'manly' behaviour may mean that young Black males do not seek help for emotional problems. A recent community study of suicidal behaviour in the UK provides some support for this interpretation of our results. ${ }^{26}$ These researchers found limited evidence of higher levels of suicidal ideation in second-generation immigrants and that ethnic minority groups were half as likely to seek medical attention following self-harm compared with White groups.

In our cohort older ethnic minority people of both genders had lower rates of self-harm than their White counterparts in all three cities (although only significantly so in Manchester and Derby). One explanation is that they have lower rates per se. Another is that older BME groups may be more reluctant to present to statutory services. In an American study, African Americans were less likely to access specialist mental health services compared with non-Hispanic White people. ${ }^{27}$ Suggested reasons for a resistance to presentation to hospital following self-harm have included that seeking help for mental distress is considered stigmatising and socially unacceptable, and that services were not accessible or considered relevant. $^{26,28}$

Clinical management is guided by knowledge of risk factors from epidemiological studies in the context of an individual patient presentation. An explanation of the less frequent specialist psychiatric assessment received by BME groups could relate to their 'low risk' clinical characteristics; for example, they were less likely to live alone, use alcohol with the self-harm attempt and have a previous psychiatric history or history of self-harm. Some BME groups were slightly less likely to be subsequently referred for formal follow-up. In addition to having apparent low-risk social and clinical characteristics, a further explanation for low-risk management might be related to how individuals from different ethnic groups communicate distress. In a recent UK study on response to childbirth, Black females had lower depression scores than White women, despite experiencing greater social adversity. ${ }^{29}$ The 'discourse of strength' (a perceived ability to deal effectively with a range of problems) attributed to young Black females may be part of their sense of identity, and admitting to depression therefore a sign of weakness. ${ }^{30}$ They may still actually experience psychological distress and resort to self-harming behaviour at a time of crisis, but this attitude of being strong may mean that these young females do not subsequently communicate risk to clinical staff.

The rate ratio for repetition of self-harm was significantly lower in all ethnic minority groups compared with White groups. This may be a result of reduced risk as they were much less likely to have those characteristics known to increase risk of suicidal behaviour. ${ }^{31}$ However, it may also be explained in terms of disillusionment with statutory services. Black and minority ethnic groups are generally perceived to have poor experiences of mental health services. ${ }^{32}$ It is possible that on initial presentation some ethnic minority groups may not have received appropriate help, which may have affected their willingness to re-present. ${ }^{33,34}$

Previous studies have found an increased risk of self-harm in young South Asian females compared with White women. ${ }^{11}$ We did not find this. There are a number of possible interpretations for the difference in results in young South Asian groups compared with previous findings and between centres. First, previous studies were carried out in Birmingham and London ${ }^{17,35}$ and not all South Asian populations are the same. For example within our three centres the proportions of the population that were of Indian, Pakistani and Bangladeshi origin varied considerably (Table 1). Our results might therefore reflect the particular mix of South Asian populations in the three centres. Second, comparative studies took place over 10-25 years ago and the young British South Asian population is likely to have changed over time. ${ }^{36}$ Third, since these findings, considerable attention has been drawn to this problem, with consequent improvement of services. ${ }^{37,38}$

The higher rate ratios observed in young South Asian people compared with young White people in Oxford in relation to the other cities might be a result of differences in the relative socioeconomic profiles between ethnic groups in different cities. Differences in the relative density of ethnic groups between cities may also explain this variation in rates. Oxford has the lowest proportion of South Asian people within its population compared with the other cities, although it had higher rates of self-harm in South Asian young males and females compared with their White counterparts. This could reflect the cultural incongruence and ecological-effect modification suggested in previous research - a negative correlation between the incidence of psychological distress and the size of an ethnic group relative to the total population. $^{8,39}$ Unfortunately, we had no measure of these contextual variables to enable examination of their potential effects.

\section{Strengths and limitations}

The strength of this study is that we used large, contemporary population-based databases from three separate centres and examined the three main ethnic groups living in the UK. The data were collected principally from urban populations and this might limit the generalisability of the findings, although the populations covered by the three centres had different socioeconomic characteristics. ${ }^{14}$ The ethnic minority categories we applied were broad and did not take account of cultural identity. ${ }^{40}$ However, it enabled estimation of precise rates and relative risks stratified by age and gender and allowed direct comparison with previous research on ethnic groups in the UK. This may have concealed differences between ethnic groups within the categories we used. All three centres may have overassigned people to ethnic minority groups compared with Office for National Statistics ascertainment procedures. Ethnicity was recorded by healthcare staff who may or may not have asked the individual to categorise themselves. Ethnicity was recorded for $75 \%$ of individuals. Ethnicity is not 
recorded comprehensively in hospital settings, although our capture rate was significantly higher than a recent survey of users of community mental health services in England. ${ }^{33}$ Even so, there is the potential for selection bias. However, when we conducted a conservative sensitivity analysis on rates of self-harm on White versus Black females aged 16 to 34 years ascribing all missing data to the White groups the conclusion was essentially unchanged.

\section{Implications for services and further research}

Those designing services for people who self-harm need to be aware of the different levels of risk of self-harm and the variations in risk characteristics in different ethnic groups. Services also should be able to respond to the varied needs within these groups. It may be that a failure of professionals to recognise cultural factors at play, and an ignorance of available services, contribute to the lack of recognition of mental health problems and subsequent failure to offer (and for ethnic minority patients to engage in) further services. The challenge is to make services more culturally sensitive. There is some evidence for effectiveness of cultural competency training in demonstrating a change in skills and attitudes of clinicians. ${ }^{41}$ Future culturally sensitive studies might help us achieve a greater understanding of the suicidal process in ethnic minority groups.

\footnotetext{
Jayne Cooper, Elizabeth Murphy, Roger Webb, Centre for Suicide Prevention, University of Manchester, Community Based Medicine, Manchester; Keith Hawton Helen Bergen, Centre for Suicide Research, University of Oxford, Department Helen Bergen, Centre for Suicide Research, University of Oxford, Departmental
of Psychiatry, Warneford Hospital, Oxford; Keith Waters, Derbyshire Mental Health Services NHS Trust Mental Health Liaison Team, Rehabilitation Centre, Royal Derby Hospital, Derby; Navneet Kapur, Centre for Suicide Prevention, University of Manchester, Community Based Medicine, Manchester, UK

Correspondence: Jayne Cooper, Centre for Suicide Prevention, University of Manchester, Community Based Medicine, Jean McFarlane Building, Oxford Road, Manchester M13 9PL, UK. Email: jayne.cooper@manchester.ac.uk

First received 1 Sep 2009, final revision 26 Feb 2010, accepted 13 May 2010
}

\section{Funding}

We acknowledge financial support from the Department of Health under the NHS R\&D Programme.

\section{Acknowledgements}

The authors would like to thank the staff at each centre for data collection and clinical staff for completion of assessment forms.

\section{References}

1 McKenzie $K$, Serfaty $M$, Crawford $M$. Suicide in ethnic minority groups. Br J Psychiatry 2003; 183: 100-1.

2 Garlow S, Purselle D, Heninger M. Ethnic differences in patterns of suicide across the life cycle. Am J Psychiatry 2005; 162: 319-23.

3 McKenzie K, Bhui K, Nanchahal K, Blizard B. Suicide rates in people of South Asian origin in England and Wales: 1993-2003. Br J Psychiatry 2008; 193 406-9.

4 Bhui K, McKenzie K. Rates and risk factors by ethnic group for suicides within a year of contact with mental health services in England and Wales. Psychiatr Serv 2008; 59: 414-20.

5 Soni Raleigh V. Suicide patterns and trends in people of Indian Subcontinent and Caribbean origin in England and Wales. Ethn Health 1996; 1: 55-63.

6 Cooper J, Husain N, Webb R, Waheed W, Kapur N, Guthrie E, et al. Self-harm in the UK: differences between South Asians and Whites in rates, characteristics, provision of service and repetition. Soc Psychiatry Psychiatr Epidemiol 2006; 41: 782-8

7 Neeleman J, Jones P, van Os J, Murray RM. Parasuicide in Camberwell: ethnic differences. Soc Psychiatry Psychiatr Epidemiol 1996; 31: 284-7.

8 Neeleman J, Wessley S. Ethnic minority suicide: a small area geographical study in south London. Psychol Med 1999; 29: 429-36.
9 Neeleman J, Wilson-Jones C, Wessely S. Ethnic density and deliberate self harm; a small area study in south east London. J Epidemiol Community Health 2001; 55: 85-90

10 Claassen D, Ascoli M, Berhe T, Priebe S. Research on mental disorders and their care in immigrant populations: a review of publications from Germany, Italy and the UK. Euro Psychiatry 2005; 20: 540-9.

11 Bhui K, McKenzie K, Rasul F. Rates, risk factors \& methods of self harm among minority ethnic groups in the UK: a systematic review. BMC Public Health 2007; 7: 336

12 Bhui K, McKenzie K. Final Report: Suicide Prevention for BME Groups in England. Report from the BME Suicide Prevention Project. Centre for Health Improvement and Minority Ethnic Services (CHIMES), 2006.

13 Department for Communities and Local Government. Index of Multiple Deprivation. Department for Communities and Local Government, 2007 (http://www.communities.gov.uk/communities/neighbourhoodrenewal/ deprivation/deprivation07).

14 Hawton K, Bergen H, Casey D, Simkin S, Palmer B, Cooper J, et al. Self-harm in England: a tale of three cities. Multicentre study of self-harm. Soc Psychiatry Psychiatr Epidemiol 2007; 42: 513-21.

15 Waters K, Stalker C. MHLT (Derby) 2007 Annual Report of Both Reported Self Harm and Mental Health Presentation, Presenting to the Derby Acute Hospitals. Derbyshire Mental Health Services Trust, 2008.

16 Hawton K, Catalan J. Attempted Suicide: A Practical Guide to its Nature and Management. Oxford University Press, 1987.

17 Bhugra D, Desai M, Baldwin DS. Attempted suicide in west London, I. Rates across ethnic communities. Psychol Med 1999; 29, 1125-30.

18 National Statistics. United Kingdom National Census, 2001. Office for National Statistics, 2001 (http://www.statistics.gov.uk/census2001/ default.asp)

19 Merrill J, Owens J. Ethnic differences in self poisoning. A comparison of West Indian and White groups. Br J Psychiatry 1987; 150: 765-8.

20 Stronks K, Kunst AE. The complex interrelationship between ethnic and socio-economic inequalities in health. J Public Health; 31: 324-5.

21 Garlow S, Rosenberg, Moore JD, Haas A, Koestner B, Hendin H, et al. Depression, desperation, and suicidal ideation in college students: results from the American Foundation for Suicide Prevention College Screening Project at Emory University. Depress Anxiety 2007; 25: 482-8.

22 Verger $\mathrm{P}$, Combes JB, Kovess-Masfety V, Choquet M, Guagliardo V, Rouillon $\mathrm{F}$, et al. Psychological distress in first year university students: socioeconomic and academic stressors, mastery and social support in young males and females. Soc Psychiatry Psychiatr Epidemiol 2009; 44: 643-50.

23 Karlsen S, Nazroo J. The relationship between racism, social class and physical and mental health among different ethnic groups in England. Ethn Health 2004; 9: S46-7.

24 Kirkbride JB, Barker D, Cowden F, Stamps R, Yang M, Jones PB, et al. Psychoses, ethnicity and socio-economic status. Br J Psychiatry 2008; 193: 18-24.

25 Sharpley MS, Hutchinson G, Murray RM, McKenzie K. Understanding the excess of psychosis among the African-Caribbean population in England: review of current hypotheses. Br J Psychiatry 2001; 178: s60-8.

26 Crawford $\mathrm{M}$, Nur U, McKenzie $\mathrm{K}$, Tyrer P. Suicidal ideation and suicide attempts among ethnic minority groups in England: results of a national household survey. Psychol Med 2005; 35: 1369-77.

27 Garland A, Lau A, Yeh M, McCabe K, Hough R, Lansverk J. Racial and ethnic differences in utilization of mental health services among high-risk youths. Am J Psychiatry 2005; 162: 1336-43.

28 Ahmed K, Mohan R, Bhugra D. Self-harm in South Asian women: a literature review informed approach to assessment and formulation. Am J Psychother 2007; 61; 71-81.

29 Edge D, Rogers A. Dealing with it: Black Caribbean women's response to adversity and psychological distress associated with pregnancy, childbirth, and early motherhood. Soc Sci Med 2005; 61: 15-25.

30 Edge D. Ethnicity, psychosocial risk, and perinatal depression - a comparative study among inner-city females in the United Kingdom. J Psychosom Res 2007; 63: 291-5.

31 Kapur N, Cooper J, King-Hele S, Webb R, Lawlor M, Rodway C, et al. The repetition of suicidal behavior: a multicenter cohort study. J Clin Psychiatry 2006; 67: 1599-609.

32 Commission for Healthcare Audit and Inspection. Variations in the Experiences of Patients using the NHS Services in England. Analysis of the Healthcare Commission's 2004/2005 Surveys of Patients. Commission for Healthcare Audit and Inspection, 2006. 
33 Raleigh VS, Irons R, Hawe E, Scobie S, Cook A, Reeves R, et al. Ethnic variations in the experiences of mental health service users in England. Results of a national patient survey programme. Br J of Psychiatry 2007; 191 304-12

34 Taylor TL, Hawton K, Fortune S, Kapur N. Attitudes towards clinical services among people who self-harm: systematic review. Br J of Psychiatry 2009; 194: $104-10$.

35 Merrill J, Owens J. Ethnic differences in self poisoning: a comparison of Asian and White groups. Br J Psychiatry 1986; 148: 708-12.

36 Platt L, Simpson L, Akinwale B. Stability and change in ethnic groups in England and Wales. Popul Trends 2005; 121: 35-46.
37 National Institute for Mental Health in England. Inside Outside: Improving Mental Health Services for Black and Minority Ethnic Communities in England. Department of Health, 2003.

38 Department of Health. Delivering Race Equality in Mental Health Care: A Summary. TSO (The Stationery Office), 2005.

39 Bhugra D, Arya P. Ethnic density, cultural congruity and mental illness in migrants. Int Rev Psychiatry 2005; 17: 133-7.

40 Bhui $\mathrm{K}$. The new science of cultural epidemiology to tackle ethnic health inequalities. J Public Health 2009; 31: 322-3.

41 Bhui K, Warfa N, Edonya P, McKenzie K, Bhugra D. Cultural competence in mental health care: a review of model evaluations. BMC Health Serv Res 2007; 7: 15 .

\section{My taster experience}

\section{Sacha Evans}

A business man who thought the CIA were 'after him', a recovering cocaine addict with financial problems and a young man refusing to engage with any treatment were some of the memorable patients I met during my taster session. In a single ward round, I managed to 'tick-off' schizophrenia, bipolar affective and borderline personality disorders. For psychiatrists, seeing these types of patient is routine; for foundation doctors, our exposure may be limited to our student attachments.

Following on from Modernising Medical Careers, foundation doctors are expected to make their career choice approximately 16 months after graduating. With only $6 \%$ of graduates being offered a psychiatry post during their foundation training few get direct psychiatry experience. To overcome this, the UK Foundation Programme Office recommends that foundation doctors undertake taster sessions, which is 3 to 5 days' work experience under the guidance of a senior clinician.

My consultant had a well-planned schedule; in 3 days, I managed to fit in a community visit, clinical governance session and audit presentation. I also gained valuable clinical contact on the ward. I became aware of some pertinent issues in psychiatric practice, such as patients' physical health and the use of crisis resolution teams and emergency psychiatric services. It gave me the opportunity to speak to trainees (at different stages of training) to gain their perspectives about a career in psychiatry and find out the all-important tips for success in the application process.

There are challenges; tasters can be difficult to arrange. Before I started, I had to organise two references, visit the human resources department and get a separate Criminal Records Bureau check. The short duration provides a snapshot, rather than the full spectrum of career opportunities in psychiatry. It also relies on having an enthusiastic and proactive sponsor. My experience was overwhelmingly positive and reinforced my belief that psychiatry is the career for me.

For more information about organising tasters see the Foundation Programme Reference Guide Appendix F: Embedded taster experiences template (downloads available from http://www.foundationprogramme.nhs.uk/pages/home/key-documents). 